\title{
Método, Análise e Verdade em Psicologia: Sobre uma Análise Institucional do Discurso
}

\author{
Method, Analysis And Truth In Psychology: \\ On Institucional Discourse Analysis
}

Método, Análisis Y Verdad En Psicología:

Sobre Un Análisis Institucional Del Discurso

Renee Volpato Viaro

\& Luciana Albanese

Valore

Universidade Federal do Paraná
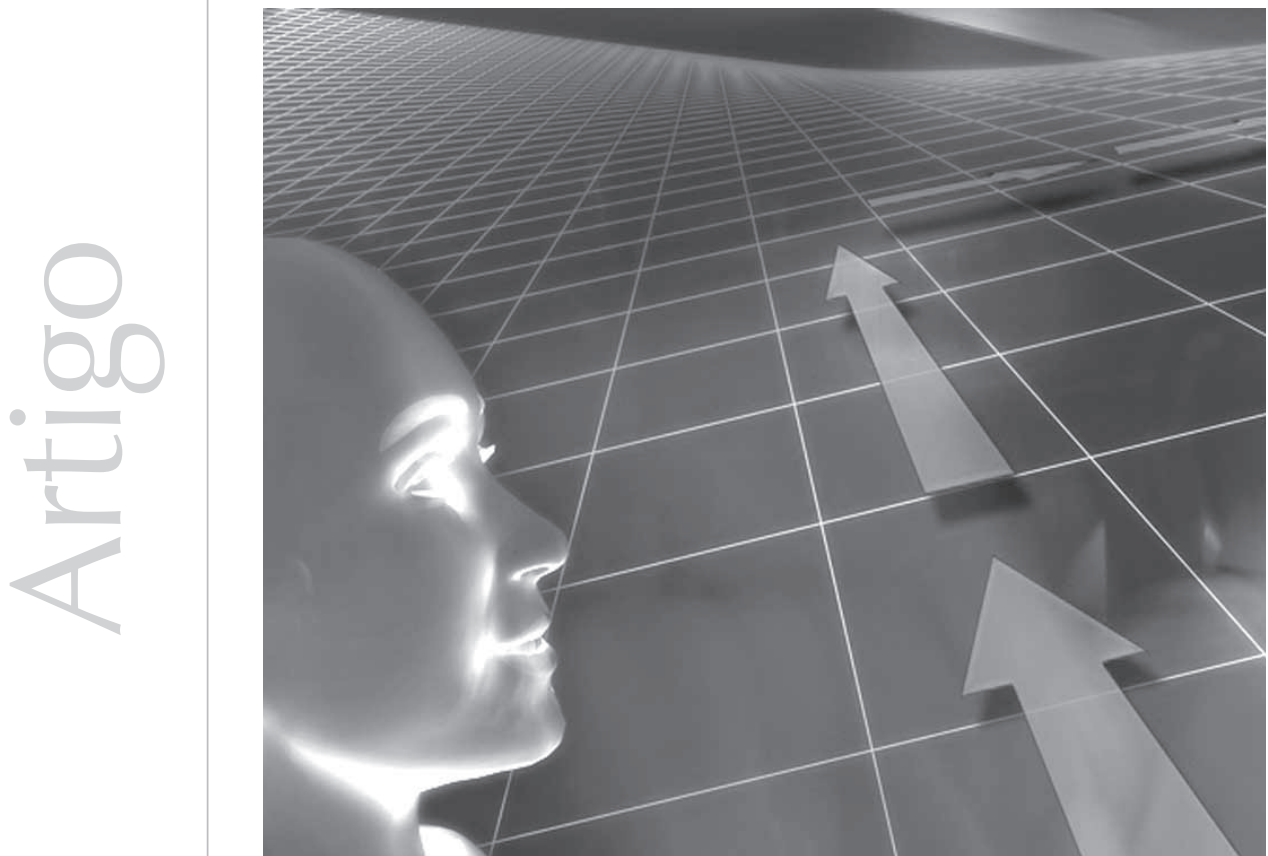
Resumo: O presente artigo objetiva discutir as implicações do método na produção da verdade em Psicologia por meio do conceito de análise tal como formulado pela análise institucional do discurso. Para tanto, elabora-se uma reflexão que parte da concepção foucaultiana de discurso em direção às noções de instituição, sujeito e análise, com as quais se trabalha na perspectiva proposta. Desenvolvida por Marlene Guirado, a análise institucional do discurso estabelece-se como uma organização de ideias que viabiliza uma analítica da subjetividade, na qual o papel desempenhado pelo próprio método passa a ser considerado na produção das verdades que formula, consideração possibilitada por uma análise que, de modo diverso de uma interpretação, interroga os modos de produção do discurso (e das verdades nele estabelecidas) ao invés de sua significação. Essa tarefa é intermediada pela análise das condições de possibilidade de enunciação e de subjetivação em um dado contexto, de onde se propõe uma prática em Psicologia que reconheça o caráter de produção artificial em contraposição ao de descoberta natural da verdade.

Palavras-chave: Metodologia. Verdade. Análise do discurso. Subjetividade.

Abstract: This article discusses the implications of the method in the production of truth in Psychology through the concept of analysis as formulated by the institutional discourse analysis. For this purpose, it prepares a reflection that starts from the foucaultian conception of discourse towards the notions of institution, subject and analysis with which it works in the proposed perspective. Developed by Marlene Guirado, the institutional discourse analysis is established as an organization of ideas that allow an analytic of subjectivity, in which the role played by the method is regarded in the production of the truths that it formulates. This account is made possible by an analysis that, differently from an interpretation, interrogates the modes of discourse production (and the truths therein made), rather than its signification, task intermediated by the analysis of the conditions of possibility of enunciation and subjectification in a given context, from which it proposes a practice in Psychology that recognizes the character of artificial production in opposition to the natural discovery of truth.

Keywords: Methodology. Discourse analysis. Truth. Subjectivity.

Resumen: El presente artículo tiene como objeto discutir las implicaciones del método en la producción de la verdad en Psicología por medio del concepto de análisis tal como formulado por el Análisis Institucional del Discurso. Para tanto, se elabora una reflexión que parte de la concepción foucaultiana de discurso hacia las nociones de institución, sujeto y análisis con las cuales se trabaja en la perspectiva propuesta. Desarrollada por Marlene Guirado, el Análisis Institucional del Discurso se establece como una organización de ideas que torna viable una analítica de la subjetividad, en la cual el papel desempeñado por el propio método pasa a ser considerado en la producción de las verdades que formula. Consideración posibilitada por un análisis que, en diferenciación de una interpretación, interroga los modos de producción del discurso (y de las verdades en él establecidas), en lugar de su significación; tarea intermediada por el análisis de las condiciones de posibilidad de enunciación y de subjetivación en un dado contexto. Desde donde se propone una práctica en Psicología que reconozca el carácter de producción artificial, en contraposición al de descubrimiento natural, de la verdad.

Palabras clave: Metodología. Verdad. Análisis del discurso. Subjetividad.

Na condição de pertencentes ao duvidoso campo das ciências humanas, os pesquisadores em Psicologia não raro se deparam com a exigência de prestar contas da validade científica de suas proposições. Resulta daí, em meio às tensões que animam campos e compreensões, não exclusivamente, mas frequentemente, o privilégio do método como ferramenta a garantir, dada a sua condição de replicabilidade, a legitimação daquilo que se pretende afirmar, com vistas a possíveis generalizações.

O rigor metodológico carregará a responsabilidade de assegurar um modo de acesso certeiro, por assim dizer, ao objeto de conhecimento que, caso bem capturado, permitirá um vislumbre de sua(s) verdade(s). Dessa forma, estruturamse maneiras de entrar em contato com o objeto de conhecimento, de adequá-lo à lógica do verdadeiro/falso, de atingi-lo sem descaracterizar seus elementos originais (ou descaracterizando-o o menos possível), de controlar as variáveis de modo a permitir a replicação do estudo, de amenizar ao máximo as influências da ação do pesquisador sobre o contexto de pesquisa, etc. Tais medidas visam à garantia de um acesso confiável ao objeto 
que viabilize ao pesquisador formular, a partir daí, proposições fidedignas, isto é, capturar, enfim, a(s) verdade(s) de tal objeto. Esse bem intencionado pesquisador, apaziguado em sua vontade de verdade (Foucault, 2008), poderá, então, dizer que seu fazer o é com ciência.

O quadro geral, e um tanto singelo, esboçado acima, constitui o ponto de partida para o objetivo do presente artigo, a saber: discutir a questão do método, em Psicologia, sob ângulo outro que permita modos outros de produção de verdades. De saída, fala-se da verdade como da ordem do produzido (e não do descoberto), perdendo-se de vista, então, qualquer pretensão a, aqui, apresentar uma perspectiva que dela mais se aproxime, pois se, com Foucault (2009c) se aborda a verdade em um horizonte eminentemente político, o que se tem são regimes de produção da verdade, e não avanços progressistas de sua descoberta. E se a inevitabilidade de tais regimes torna inviável, por um lado, a afirmação de referenciais mais verdadeiros, ela permite, por outro, a intervenção sobre seus modos de produção, sem com isso supor que a verdade seria libertada dos regimes de produção. A perspectiva a ser apresentada submete-se também a um regime, não fazendo crer a libertação da forma pura da verdade, mas a possibilidade de intervir em seus modos de produção.

Apresenta-se, então, uma perspectiva que se organiza de maneira singular no trato do método, a análise institucional do discurso analítica desenvolvida por Marlene Guirado, livre-docente do Instituto de Psicologia da Universidade de São Paulo - que, ao constituir-se na interface dos discursos psicanalítico, filosófico e linguístico, propicia um reposicionamento do olhar sobre aquilo que já tomou formas íntimas e conhecidas, auxiliando, assim, na operação de cortes de moldes bem sedimentados - "cortes que fazem pensar" (Guirado, 1987), pois, assim como em Foucault (2009b, p. 28), nessa perspectiva, considera-se que "[...] o saber não é feito para compreender, ele é feito para cortar".

Calcada no pensamento de Freud, Maingueneau e Foucault, Guirado cunha a análise institucional do discurso (AID) como uma organização de conceitos que resulta em uma analítica da subjetividade (2009). A isso se retornará adiante. Por ora, cabe destacar a possibilidade demonstrada pela autora de configurar o método como uma estratégia de pensamento, que toma a Psicologia como instituição do conhecimento e da prática profissional onde e como ela se dê, pela ação direta de seus atores, de forma que, ao invés de uma Psicologia institucional pensada como área de atuação, o que se coloca em questão é um modo de pensar: "Nossa proposta visa dizer não de uma área de atuação, mas de um certo dispositivo metodológico, de um certo modo de produzir... Psicologia" (Guirado, 2010, p. 44). Tal estratégia do pensamento baliza-se por alguns conceitos centrais que permitem operacionalizar um modo de análise e que serão abordados a seguir.

Inicialmente, será apresentado o conceito de discurso, seguido pela problematização foucaultiana acerca do imbricamento entre método e verdade para, finalmente, em uma diferenciação entre análise e interpretação, apontar-se de que modo tal problematização pode ser analiticamente respondida pela metodologia desenvolvida por Guirado. Com essa discussão, espera-se ampliar o campo de compreensão daquilo que, em Psicologia, comumente se denomina método, operando um deslocamento que permita tratá-lo como estratégia, deslocamento cujo principal efeito é o reconhecimento do caráter de produção artificial, e não simplesmente de descoberta natural da(s) verdade(s). 


\section{Discurso}

Diante da necessidade de pensar na singularidade subjetiva sem negligenciar as formações sociais, Guirado desenvolve um intercampo discursivo capaz de, na mesma análise, dar forma a esses campos sem incorrer em dicotomia. Trata-se da sistematização de um esquema de pensamento que estrutura um modo de fazer Psicologia que, longe de qualquer pretensão totalizadora, joga com a ideia de que o método configura um recorte analítico sempre parcial e situado no tempo e no espaço, recorte que define, ainda, as condições de possibilidade do campo de enunciação do pesquisador, como se verá adiante. Em tal recorte, três conceitos são essenciais, "uma vez que, com eles e por eles, pode-se falar do trânsito ou do atravessamento de um mesmo esquema de pensamento em práticas diferentes como a pesquisa e o atendimento clínico" (Guirado, 1997); são eles: discurso, instituição e sujeito.

O termo discurso é bastante familiar às leituras psicológicas, sendo usualmente compreendido como forma de expressão de uma realidade. Nessa perspectiva, realidade e discurso guardam entre si uma relação de exterioridade, como bem observa Maingueneau, linguista embasado em Foucault e tomado como referência para a elaboração da AID de Guirado:

\begin{abstract}
A concepção espontânea que a gente tem do discurso, da linguagem em geral, é a idéia de que a realidade é fundamentalmente não-verbal e que o discurso chega depois para refletir essa realidade. Na concepção clássica, a linguagem é uma representação da realidade (Maingueneau citado por Guirado, 2000, pp. 26-27)
\end{abstract}

1 Pensar no discurso como regramento é fundamental para o estabelecimento da proposta institucional de Guirado, como se verá adiante. expressão de um pensamento. Mas será sempre esse intermediário que fica entre o sujeito cognoscente e a realidade alvo de sua atenção. E, uma vez que esta última existe por si só, como realidade prévia e independente, justifica-se a busca pelo conhecimento de sua objetividade. Palavras (como discurso representativo) e coisas (como realidade já dada) estariam em âmbitos distintos e caberia ao sujeito cognoscente bem operar um método que permita, com as palavras, fidedignamente falar sobre a realidade das coisas. Palavras e coisas, então, pré-existem, verdades as habitam silenciosa e pacientemente à espera do golpe de lucidez que as revelarão. Se bem sucedida, a operação rende uma proposição científica, isto é, a formulação (por meio do discurso) da verdade sobre o objeto de estudo (que se deu por meio do método). As palavras transmitiriam, finalmente, aquilo que o método é capaz de descobrir sobre as coisas. O discurso traduz o método e a verdade, traduttore, traditore.

Não sendo gratuita a referência a As Palavras e as Coisas (Foucault, 2007), faz-se necessário ressituar o discurso na AID. Está-se agora no âmbito das ideias de Michel Foucault, autor segundo o qual o discurso se define como formação discursiva, isto é, como "um conjunto de regras ${ }^{1}$ anônimas, históricas, sempre determinadas no tempo e no espaço, que definiram, em uma dada época e para uma determinada área social, econômica, geográfica ou lingüística, as condições de exercício da função enunciativa" (Foucault, 2005, p. 133).

Mas, se o discurso regula a função enunciativa, estar-se-á a ele sempre sujeitado? Sim, se com isso se entender que falar é entrar em uma instituição que domina o falante e que, no mesmo ato de dominação, legitima suas falas - é precondição para qualquer ato de fala; não, porém, se se entende que essa ordem não está em um além que determina as enunciações unicamente; não, se essa ordem 
for concebida como constantemente refeita pelas relações cotidianas, como situada no tempo e no espaço e ao alcance de cada (enunci)ação. Destarte, discurso implica mais do que falar simplesmente, é um modo de agir, de um agir perigoso que assume riscos, afeta ou resiste, fere ou reconcilia.

[...] Falar é fazer alguma coisa - algo diferente de exprimir o que se pensa, de traduzir o que se sabe e, também, de colocar em ação as estruturas de uma língua, mostrar que somar um enunciado a uma série preexistente de enunciados é fazer um gesto complicado e custoso que implica condições [...] e comporta regras [...] (Foucault, 2005, p. 237).

Não considerar mais o discurso como exclusivamente pertencente ao âmbito das palavras e/ou reflexo das coisas e tratá-lo como um regramento definidor das condições de exercício da função enunciativa permite aproximações à problemática do método - foucaultiano ${ }^{2}$, inclusive, uma vez que a análise arqueológica "[...] define as regras de formação de um conjunto de enunciados" (Foucault, 2005, pp. 191-92). Além disso, é válido salientar que os discursos são historicizados, são acomodados às diversas situações para se estabelecerem como ato impositivo, ato de verdade, e, quase sempre, como ato de força. A perspectiva foucaultiana salienta "[...] a enunciação de discursos que funcionam entre diferentes práticas como justificação racional de verdade, como se fossem verdadeiros" (Candiotto, 2006, p. 66), evidenciando que a verdade não é tomada como naturalidade descoberta pelo sujeito do conhecimento, mas como produção histórica das "regras segundo as quais, a propósito de certas coisas, aquilo que um sujeito pode dizer pertence à questão do verdadeiro e do falso" (Foucault citado por Candiotto, 2006, p. 68).

Com essas aproximações, distancia-se de uma concepção representacional do discurso para dar lugar ao seu caráter de acontecimento, de ato. O discurso participa, assim, da determinação das condições de possibilidade de surgimento e de ordenação dos saberes, e dessa forma, insere-se diretamente na realidade como uma atividade, deixando de ser somente sua representação, seu reflexo, sua tradução. Ele passa a constituir domínios, objetos, métodos e técnicas passíveis de serem pensadas em dado momento histórico; ele é parte constituinte/constituída da realidade que as palavras representariam apenas. Tal tese será retomada por Guirado:

\begin{abstract}
Assim, quando se fala, fala-se sempre do interior de uma instituição discursiva, uma instituição que: antecede-nos logicamente, rouba-nos a autoria de nosso texto, inserenos numa ordem de lugares de enunciação, instaura as possibilidades de sentido e de significação, é ocasião de reconhecimento e de toda subjetividade possível (Guirado, 1997, p.147)
\end{abstract}

Se o discurso dispõe condições de enunciação e lugares, e se aí justamente relações de poder-saber acontecem³ ${ }^{3}$, ele, então, não é exatamente palavra, mas também não é exatamente coisa, é regramento historicamente situado a partir do qual certas condições de possibilidade (das palavras e das coisas) se dão. É, finalmente, regime discursivo, no qual efeitos de poder próprios do jogo enunciativo constituem palavras e coisas qualificadas como verdadeiras (ou falsas) e mecanismos de sujeição a elas vinculados. É prática discursiva.

\section{Método (d)e verdade}

A concepção foucaultiana do discurso conduz a um entendimento bastante diverso acerca do método, da verdade, e de suas funções, bastante diverso, ao menos, daquele que se esboçou anteriormente (sobre o método empírico, em que o discurso traduz o método e a verdade), pois quando considerado como ato, o discurso deixa de ser simplesmente o mediador simbólico entre pesquisador (munido de seu método) e objeto de estudo 
"Assim, a verdade
não tombaria
do Cosmos, das
idéias acima
de qualquer
suspeita, à Terra,
mas das relações
entre os homens,
inserindo-se
agora em jogos
que regulariam
o modo de
produção de
seus enunciados
e as regras de
produção de
sua legitimidade"
(Birman, 2002, p.

307), para ser o constituinte desses termos, uma vez que é no e pelo discurso que condições de possibilidade de posturas do sujeito cognoscente, de métodos, objetos e enunciações a seu respeito podem se dar.

O que está em questão é o regime discursivo e a forma como ele determina os modos de produção de conhecimento válidos, regime nada exterior, mas configurado pelas práticas vigentes em um dado contexto científico de uma dada época, sendo então relativo, a despeito dos ares de naturalidade que tenda a tomar. "Assim, a verdade não tombaria do Cosmos, das idéias acima de qualquer suspeita, à Terra, mas das relações entre os homens, inserindo-se agora em jogos que regulariam o modo de produção de seus enunciados e as regras de produção de sua legitimidade" (Birman, 2002, p. 307), a verdade como produção discursiva, portanto, sendo que, por verdade, Foucault não faz menção ao

[...] Conjunto das coisas verdadeiras a descobrir ou a fazer aceitar, mas [ao] conjunto das regras segundo as quais se distingue o verdadeiro do falso e se atribui ao verdadeiro efeitos específicos de poder, entendendo-se também que não se trata de um combate em favor da verdade, mas em torno do estatuto da verdade e do papel econômico-político que ela desempenha (Foucault, 2009c, p. 13)

E, se a verdade é produzida por meio de um jogo regrado,

[...] Não estaríamos mais diante de uma progressão infalível do espírito em direção à verdade, mas de diferentes modalidades de conceber o sujeito, o mundo, as coisas e os objetos, isto é, estaríamos lançados decididamente em diversos jogos de verdade, sem qualquer hierarquia valorativa quanto à veracidade entre eles (Birman, 2002, p. 318)

Assim, ao invés de garantir objetividade, entende-se que o método (como organização das formas de se conhecer) garante objetivação.
Logo, não se toma uma objetivação prévia, como se o objeto de conhecimento fosse uma constante a ser compreendida pelos diversos (e supostamente cada vez mais apurados) modos de conhecimento; não é uma história dos objetos que Foucault desenrola, mas uma história dos modos de objetivação, objetivação essa sofrida pelo próprio homem inclusive: o ser humano, por exemplo, tal como concebido pelas ciências humanas, é, segundo Foucault (2007), um produto moderno possível somente em um dado momento histórico graças a uma configuração específica de determinados campos de saber. Essa não seria uma constante, enfim, abordada em suas múltiplas facetas (sociais, psicológicas, antropológicas, sexuais, etc.), daí, como se verá adiante, o modo específico de a AID conceber o sujeito como uma estratégia de pensamento que permite operar com a singularidade psicológica sem objetivar um sujeito substancializado que tomaria o lugar de uma objetivação prévia (a ser assumida e mantida como se o próprio método da AID não fosse seu constituinte).

É interessante observar que, no texto Vontade de Saber (1984), ao intitular um dos capítulos como Método, Foucault nada mais faz senão expor um conceito: poder. No cerne do método, encontra-se, pois, um conceito, a organização de uma ideia, uma estratégia de pensamento. Sobre isso, Guirado comenta:

[...] Parecia fazer todo sentido assim interpretar a relação título/texto, na medida em que essa interpretação parecia se ajustar ao entendimento de que a verdade, como se configura por um saber, está creditada como verdade antes mesmo dos resultados do estudo que parece revelá-la. Nossas pesquisas, por exemplo, produzem como resultado aquilo que é do escopo do recorte que, mais ou menos conscientemente, definimos nas teorias que informam nosso pensamento, pelo que entendemos por produção de conhecimento, por ciência, por pesquisa, etc. Os procedimentos dão o escopo do campo das verdades possíveis, ou ainda, por sua repetição à exaustão, 
conforme os cânones do saber e do conhecimento professados, facilitam, de um lado, o reconhecimento de uma verdade e de uma realidade que se expõem ao estudo e à análise e, de outro, o desconhecimento de seu caráter de produzidas, de acordo com as lentes, ou melhor, com a leitura que delas se faça. Os procedimentos por suas fundações conceituais se põem no lugar do sujeito fundador da experiência do conhecimento (Guirado, 2010, p. 70).

O método configura, desse modo, um recorte analítico que delimita o campo possível de objetos e verdades a serem atingidos. As fundações conceituais do método e suas decorrências é que ficam evidenciadas: quando considerado como campo conceitual, cai por terra sua pretensão universalizante, movimento inverso daquele encontrado em uma metodologia empírica, cuja pretensão ao universal eclipsa a parcialidade conferida por sua fundação conceitual.

Considerando-se, então, que aquilo normalmente reconhecido como verdadeiro não está no objeto de conhecimento (uma vez que ele não preexiste, torna-se tal em um ordenamento específico), nem no sujeito (já que ele não é essência, mas torna-se tal nas práticas em que é tomado), pode-se afirmar que o método (como intermediário ideal entre objeto e sujeito) ocupa lugar central na problemática da verdade. E isso é válido tanto para a perspectiva corrente que faculta ao método o papel de procedimento universal garantidor da veracidade da proposição quanto para a perspectiva foucaultiana, que não o trata mais como procedimento universalmente objetivo, mas como parte de um conjunto de práticas discursivas objetivadoras, práticas situadas que ordenam o campo de possibilidades passíveis de serem formuladas a partir de determinada perspectiva conceitual. O método produz a verdade, não a revela. A verdade é discursivamente instituída, dir-se-ia com Guirado (2009). Mas... como compreender uma verdade que, ao invés de se dar, é instituída? Ora, ressituando aquilo a que comumente se chama de instituição, de modo que o termo possa operar como um mediador conceitual que permita uma prática psicológica que leve em conta a concepção foucaultiana de discurso. Assim, pode-se atuar na Psicologia tomando a verdade como resultado de um jogo plasmado no espaço social e legitimado no âmbito da história pelo seu uso corrente (Birman, 2002).

\section{Matrizes institucionais do sujeito psíquico da AID}

A noção foucaultiana de discurso é fundamental para abordar outros dois conceitos estruturantes da AID: instituição e sujeito. Tomar o discurso como regramento da função enunciativa é aproximar-se da própria instituição, o que permite entrever a proximidade entre tais noções, pois, por instituição, Guirado compreende

[...] Um conjunto de práticas que se repetem e que, enquanto se repetem, se legitimam, sendo a legitimação uma espécie de naturalização daquilo que é instituído. Em algum momento da história e para dar conta de certas necessidades e urgências sociais, os homens foram se organizando de determinada forma, e essa forma de organização ou de relação vai-se perpetuando; são as instituições. Tendemos a dizer, em meio à reprodução das relações e exatamente porque desconhecemos sua origem, que as relações são assim por natureza; não as consideramos como instituídas e sim, como se tivessem sido criadas por Deus! Tal legitimação acontece por um efeito de reconhecimento das práticas como as únicas possíveis e um desconhecimento de outras modalidades de relação (Guirado, 1997)

A instituição, assim como o discurso, não se configura como um âmbito externo às práticas daqueles que a vivem, pelo contrário, ela se configura justamente em seu fazer cotidiano, seja esse um fazer da/na Psicologia, da/na família, da/na sociedade, etc, fazer cuja resultante principal é a constituição 
de um objeto. Toda instituição configura um objeto institucional, isto é, "aquilo em nome de que a instituição se faz, e sobre o que reivindica monopólio de legitimidade" (Guirado, 2010, p. 130). E, como toda instituição, a AID também constitui seu próprio objeto: “[...] as relações, mas não as que materialmente se dão, e sim, tal como imaginadas, percebidas, representadas pelo sujeito" (Guirado, 1986, p. 71). As relações são consideradas em suas dimensões de reconhecimento e desconhecimento, portanto, é a eleição de tal objeto o que permite operacionalizar a AID como uma analítica da subjetividade, pois entende-se que são nas e pelas relações institucionais que toda e qualquer subjetividade pode ser concebida. "A subjetividade, assim pensando, é constituída ou, melhor, matriciada no conjunto das relações institucionais, e isso não exclui a questão da singularidade psíquica. Entende-a, porém, enquanto organizações particulares de uma história de relações e de vínculos" (Guirado, 1997).

Guirado (2009) propõe um sujeito que se pode dizer psíquico por ser institucional, uma vez que o próprio âmbito do psíquico é compreendido como efeito institucional, isto é, como efeito de reconhecimentos da naturalidade e de desconhecimentos da relatividade dos lugares institucionaisdiscursivos que se ocupam e se reeditam em uma história de vida. Assim, ao constituirse em meio a relações e vínculos afetivos institucionalizados (como os familiares, por exemplo), esse sujeito organiza e é organizado pela instituição, não podendo existir fora dela, nem ela sem a ação dele.

Para conceitualizar tal compreensão, Guirado (1995) utiliza a metáfora do sujeito-dobradiça como possibilidade de entrever, ao mesmo tempo e no mesmo ato da enunciação, a produção de uma singularidade psíquica e de suas condições institucionais de produção. O sujeito pode, então, ser visto como efeito das práticas (discursivas) institucionais, isto é, como efeito do jogo de reconhecimento e de desconhecimento - das práticas instituídas, de si, do outro, e de si e do outro nessas práticas - que se produz no discurso. $\mathrm{O}$ sujeito não é visto como causa, configurada por uma interioridade imanente, como se costuma formalizar na maior parte das teorias psicológicas, mas como produto de sua história de vínculos institucionais.

Esse conceito dobradiça de sujeito é, ainda, uma espécie de desdobramento daquilo que Foucault denominou modos de subjetivação: se o regime discursivo instituído possibilita a constituição de objetos de saber, e se aí se inclui o próprio ser humano como objeto formalizado, Foucault afirmará que, no mesmo movimento de constituição desse objeto, a individualidade daí advinda apropria-se da objetivação sofrida subjetivando-se, um modo de se experienciar conduzido pela (re)apropriação que os indivíduos fazem do discurso que os objetivou. É importante ressaltar que Foucault não concebe uma subjetividade singular, muito menos interiorizada. A dispersão do sujeito e a sobredeterminação da subjetividade marcam sua obra. Guirado, no entanto, ao formular o conceito dobradiça de sujeito, matiza singularmente a subjetividade que Foucault somente enuncia (Ribeiro, 2007), uma subjetividade-efeito que poderá ser delineada pela análise de seu discurso.

Apesar de conceber um sujeito que possa soar um tanto dessubstancializado, tal modo de pensá-lo não exclui, todavia, a possibilidade de atribuir-lhe o atributo de psíquico, desde que por esse termo se entenda o modo singular com que se organizam e se rearranjam sentidos nas pautas discursivas instituídas; assim, à sua maneira, mesmo assujeitado à ordem do discurso, irá legitimar ou subverter práticas e lugares subjetivos, e isso sempre no discurso, daí a importância de, nessa estratégia de pensamento, ter 
precisado esse conceito, pois entende-se que é no discurso, em sua instituição, que toda subjetividade acontece: uma subjetividadeefeito dos jogos discursivos.

É tendo em vista uma subjetividade matriciada no discurso que se pode tratar a AID como uma analítica da subjetividade, já que sua análise concernirá justamente à cena discursiva instituída e aos efeitos subjetivos daí decorrentes, isto é, aos efeitos de reconhecimento e desconhecimento acerca dos lugares ocupados por si e pelo outro, de seus desníveis (ocasião de exercício de poder), das expectativas atribuídas, acatadas e negadas, dos múltiplos atravessamentos que habitam um discurso (tornando-o heterogêneo e opaco), das repetições exercidas nas relações interpessoais...

Assim, ao ser (co)instituída em regimes discursivos, a verdade sobre uma subjetividade pode ser tomada como aquela passível de ser reconhecida (e desconhecida) como tal - em um dado conjunto de relações situado no tempo e no espaço, sempre. E o mesmo pode ser dito sobre o método (seja ele afirmador das verdades de uma pesquisa acadêmica ou de uma sessão psicoterapêutica): sua fundação em um campo discursivo gerará efeitos de reconhecimento de sua naturalidade verdadeira e desconhecimento de sua relatividade instituída.

\section{Análise institucional do discurso e análise}

Diante da problemática levantada acerca do imbricamento entre método e verdade e munidos dos conceitos fundamentais da AID, pode-se avançar para a exposição do conceito de análise viabilizador dessa analítica da subjetividade como alternativa viável para uma prática psicológica que considere o papel desempenhado por seu método nas conclusões que possa esboçar.
Ter um campo conceitual como metodologia significa algum reconhecimento (pois sempre parcial) do caráter produzido da verdade que se afirma, reconhecimento de que essa produção é permeada por relações de poder, de que uma vontade de verdade se apóia em um suporte institucional cujo controle ordena as possibilidades discursivas (Foucault, 2008). Isso significa um olhar de estranhamento àquilo que se credita, para que a verdade a ser formulada possa ser reconhecida como produto do que a fizeram ser (Guirado, 2010).

Uma vez que o discurso seja considerado como ato, não faz mais sentido um posicionamento que busque dissipar sua nebulosidade e reconstituir por meio de interpretações sua relação de representação de uma realidade interna e/ou externa, isto é, de fazer dele um método de desvelamento da verdade, mas antes, trata-se de analisar seu modo de produção e, de quebra, da verdade que o paciente (tendo em vista um setting clínico) construirá, ao invés de descobrir, sobre si. É aí que o apelo a uma análise pragmática se faz.

Com uma escuta assim informada [pela análise pragmática], podemos ficar atentos ao modo como aquele que nos fala constrói o discurso. Além disso, podemos ampliar as possibilidades de reconstrução de sentidos daquilo que é dito. Nós, psicólogos, temos o (mau) costume de ouvir e traduzir por fantasia, imediatamente, o que ouvimos, devolvendo a tradução numa sentença (gramatical, na melhor das hipóteses) que chamamos de interpretação (Guirado, 1997, p.148)

Para a apresentação em pauta, o termo análise será estabelecido em contraposição ao termo interpretação. E, de saída, ficam assinaladas as compreensões a serem expostas, quais sejam, a da interpretação como método que assume uma objetivação prévia a ser desvelada e a da análise como método que, ao invés de descobrir e/ou interpretar a verdade sobre um objeto previamente assumido, faz uso de um campo conceitual que funciona como um 
operador analítico cuja principal diferença é a possibilidade de configurar algo que não existia anteriormente.

Se até aqui a contraposição foi marcada em relação ao método empírico, a partir de agora o será em relação a uma hermenêutica. E, para tanto, uma interface com o discurso psicanalítico será constituída, supondo algum conhecimento, por parte do leitor, dos princípios desse discurso. A psicanálise será tomada como instituição do conhecimento e da prática clínica, isto é, como um conjunto de relações que se repetem e, nessa repetição, se legitimam, sendo que, ao contrário do que pode soar ao leitor não familiarizado com o discurso da leitura institucional, uma interface com a psicanálise não é estranha ao campo da proposta de análise em pauta, porque, como já mencionado, a AID configurase justamente na interface dos discursos psicanalítico, filosófico e linguístico.

Para justificar o procedimento analítico de Freud no horizonte de uma hermenêutica e daí extrair algumas decorrências, faz-se um apelo à exposição feita por Foucault (1980) em 1964, cujo título é: Nietzsche, Freud e Marx.

Nessa ocasião, Foucault toma as técnicas de interpretação desses três expoentes como objeto de sua apreciação. Para estabelecer a caracterização do sistema de interpretação próprio do século XIX, no qual Freud, Nietzsche e Marx figuram como maiores representantes, Foucault o contraporá ao sistema vigente no século XVI (calcado na semelhança), de maneira a eleger os três pensadores como aqueles que nos situam diante de uma nova possibilidade de hermenêutica (que Foucault nomeará hermenêutica moderna). Tal possibilidade comporta, segundo o autor, três aspectos essenciais: "o caráter infinito da tarefa de interpretar, o fato a isso ligado de uma interpretação ser, sempre, interpretação de outra interpretação, o fato de o princípio da interpretação nada mais ser do que o próprio intérprete" (Guirado, 2010, p. 179). Foucault faz uma refundação da hermenêutica, uma leitura específica na qual se pode identificar uma hermenêutica freudiana. De acordo com Guirado, a leitura de Foucault sugere que, ao interpretar, por exemplo, sonhos e na análise de Dora, Freud não realiza uma re-flexão

[...] A respeito da interpretação como procedimento, em seus alcances [e] em seus limites. O que há é uma farta demonstração de funcionamento inconsciente como mecanismos de deslocamento, condensação e figurabilidade que ocultam e revelam, ao mesmo tempo, o que está censurado à consciência e que só pela interpretação poderia a ela se articular novamente. É assim que se indica que em algum tempo e lugar inscreveu-se uma verdade inconsciente a que a psicanálise, pelas interpretações que suas teorias convictamente animam, pode ter acesso (Guirado, 2010, p. 180)

A inconclusão constitutiva da tarefa de interpretar (característica da hermenêutica moderna) se evidencia em Freud quando o trabalho interpretativo é eleito como articulador ao nível da consciência daquilo que uma interpretação prévia identifica:

Freud não interpreta símbolos, mas interpretações. Com efeito, porque sob sintomas, que é que descobre Freud: não descobre, como é vulgar dizer-se, 'traumatismos', antes rouba à luz do dia fantasmas, com a sua carga de angústia, ou seja, um emaranhado cujo ser próprio é fundamentalmente uma interpretação (Foucault, 1980, p. 17)

Desse modo, o procedimento interpretativo adquire a característica de legitimador do aparato conceitual (também interpretado/ interpretativo) que o forja, legitimando-o como verdade, uma verdade inconsciente previamente assumida a ser revelada pelo procedimento interpretativo do analista. Este último adquire, por sua vez, a característica de veiculador, por assim dizer, de verdades que se autoevidenciariam nas manifestações de 
sua latência, ocupando o lugar daquele que escuta e transmite as verdades inconscientes do paciente.

Nesse sentido, desenvolvem-se as reflexões de Guirado tangentes aos pressupostos teóricos e aos seus efeitos na prática do psicólogo. Tal reflexão considera que não apenas o paciente constitui o discurso em análise, não somente seus conteúdos e enunciados são ali considerados, tampouco somente a reação do analista a partir daquilo que o paciente articulou, mas o próprio discurso do analista, ou ainda, seus pressupostos psicanalíticos diariamente levados aos atendimentos farão parte do discurso em análise. O analista, de imediato, também configura a cena discursiva, no mínimo, com suas expectativas e pressupostos em relação à psicanálise que está se propondo a fazer e com os fundamentos conceituais de seu método; fica, assim, diretamente envolvido como agente no contexto analítico. O analista passa a constituir ativamente o discurso em análise, seja através dos sentidos que atribui à fala do paciente, daquilo que entende que deve fazer como analista, do que é um processo de análise, seja através de quem é o sujeito que ali se presentifica... Todo um suporte institucional dessa vontade de verdade é reconduzido e reconstituído a cada interpretação. Em outras palavras, pode-se dizer que, na cena analítica, o psicanalista atua, de certa forma, a sua relação com a psicanálise por meio da escuta que faz do paciente, não sem o consentimento deste último, que se expõe a esse aparelho institucional quando o procura, e não de maneira arbitrária, mas, como diz Guirado (1995), o analista simplesmente ouve com as palavras que tem para ouvir - com seu método.

Tal fato não representa nenhuma exclusividade psicanalítica, diga-se de passagem, uma vez que todo e qualquer método se fundamenta em pressupostos teóricos que exercerão seus efeitos no reconhecimento das verdades por ele possibilitadas e no desconhecimento de outros modos de se fazer/ser. Nenhum mal a ser perseguido, portanto, porém, na argumentação aqui erigida, uma dinâmica a ser reconhecida e quem sabe mobilizada.

Essa consideração do discurso do analista como constituinte do discurso em análise representa, grosso modo, a diferenciação entre interpretação e análise em pauta, isso porque considerar o discurso do analista como parte do discurso em análise é índice de reconhecimento do contexto ${ }^{4}$, característica de uma análise pragmática, o que, de acordo com a leitura de Guirado, não é o caso em uma interpretação, ou não da mesma forma:

\footnotetext{
O ato de interpretar [...] porta as marcas do discurso da psicanálise como instituição [...]. É um de seus mais eficazes instituintes. É o procedimento que aciona, ao mesmo instante e movimento, expectativas, conceitos, pressupostos e certezas mais ou menos encobertos e sugestivos da verdade sobre o que diz aquele que se põe em análise. $\mathrm{E}$ isso com a naturalidade e legitimidade de qualquer dispositivo discursivo-institucional (Guirado, 2010, p. 160)
}

A argumentação apresentada vem se direcionando no sentido de delinear a interpretação como ato instituinte que presta alguma estabilidade ao dispositivo clínico por ocasionar a reiteração de uma verdade já inscrita em um horizonte anterior à cena imediatamente configurada, uma verdade já prevista em uma anterioridade em relação ao contexto ali presente. E é na mobilização desse possível ensimesmamento que a estratégia de pensamento de Guirado atua. Seu apelo à análise pragmática vem a título de "dar à clínica psicanalítica um perfil diferenciado e móvel, que não se fecha sobre si mesmo" (Guirado, 2010, p. 182).

Foca-se, a partir de agora, em que consiste tal modo de análise e em que se distancia de uma interpretação. Antecipou-se acima 
o papel do contexto nessa diferenciação, e, após, reafirma-se que a preocupação com o contexto de análise provém do entendimento pragmático da linguagem que, segundo Guirado (2009), permeia de maneira implícita as análises e os escritos de Foucault.

A partir de Austin (junto a Wittgenstein), expoente da filosofia pragmática, a linguagem como representação é golpeada para ceder lugar ao seu valor performático, ou seja, o da descrição de uma realidade para aquilo que o discurso mostra enquanto diz, reposicionamento que traz consigo o contexto como gestor de sentidos das falas que se dão em determinada cena. Para o rigor do entendimento pragmático, a relação texto-contexto precisa ser subvertida:

Temos sempre a idéia de que o contexto está ao redor do texto, está fora do texto. Mas o contexto está também na cabeça das pessoas que estão no contexto... Um contexto não é uma realidade objetiva, é algo que os parceiros de fala têm na cabeça. Cada um define, por intermédio de sua fala, o contexto no qual está falando. Os falantes cooperam ou brigam para definir o contexto no qual estão falando. O discurso não está somente no contexto, mas está sempre construindo esse contexto. O contexto é uma realidade dinâmica. Se você está falando com um paciente e você está no papel do terapeuta, e num dado momento ele procura mudar as regras do jogo e dizer algo, implicando o terapeuta num outro tipo de relação, ele está introduzindo modificações no contexto. Se você aceitar essa modificação, o contexto vai modificarse. Ou você pode recusar essa modificação e indicar, de um modo implícito, que você quer ficar dentro de tal contexto. Assim, o contexto é uma realidade negociada. Não é uma coisa dada (Maingueneau citado por Guirado, 2000, p. 30)

Logo, um enunciado é tomado em um quadro de referência que, além de ditar as condições de possibilidade daquele enunciado, está presente, está atualizado dentro do próprio enunciado. O contexto é discursivamente constituído, ditando as regras de produção do discurso ao mesmo tempo em que é recriado pelos discursos ali produzidos. $\mathrm{O}$ próprio contexto, tal como apreendido pela pragmática, diz de um ordenamento instituído - destacando a importância do contexto como operador conceitual que permite ao psicólogo abordar as falas que se dão em um quadro imediato como constituídas pelo e no ordenamento discursivo-institucional (inclusive as suas próprias).

Quando entendido como realidade dinâmica constantemente recriada pelos falantes e que, além disso, pode ressituar a relação estabelecida, o contexto se torna gerador/ aplacador de expectativas na medida em que endossa as tensões, ou melhor, os jogos de poder que constituem e permeiam as relações humanas, inclusive as ditas terapêuticas ou analíticas. Com a concepção de discurso que informa a AID, entende-se que não há qualquer neutralidade acerca do exercício de forças na relação clínica, ou melhor, do ponto de vista foucaultiano, tal neutralidade é inexistente e impossível em qualquer relação, já que o poder é constitutivo de toda relação social.

O contraponto à análise pragmática então vislumbrada pode ser reconhecido nos destaques feitos àquilo nomeado como hermenêutica freudiana.

Ainda que avançando de uma hermenêutica clássica, com interpretações analógicas, para o que Foucault entendeu como hermenêutica moderna [...], Freud esbanja atenção ao que considera ser o fenômeno transferencial, e em nenhum momento lhe ocorre que o discurso em análise supunha o da própria psicanálise; ele é o constituinte desse contexto. [...] Mesmo quando considerou a transferência de seus pacientes, e mesmo quando, engenhosamente, redesenhava a rede mágica inconsciente, com atentas perguntas e escutas, Freud não pode dar ao contexto a consideração que a filosofia analítica e a análise pragmática do discurso Ihe dão (Guirado, 2010, p. 185) 
Contudo, fazendo justiça a Freud e à exposição de Guirado, é importante ressaltar que o próprio Freud, em certa medida, desestabiliza esse modo de operar interpretativo, ora constrangendo nossa vontade de verdade (como, por exemplo, no caso Schreber), ora firmando um modo de operar calcado em construções. Entretanto, não é necessário grande esforço para reconhecer o modo interpretativo aqui descrito nos fazeres cotidianos.

Os disparadores analíticos que vêm da Lingüística permitem deter a atenção no modo de construção do discurso, no como se faz a fala, nas recorrências, nas relações entre os termos, nas associações e nas descontinuidades. Permitem uma espécie de mapeamento do terreno ou da tessitura discursiva. E isso pode, então, levar-nos a fazer pontuações que permitam deslanchar a fala do paciente para rumos raramente previsíveis. Os sentidos que se possam reconstruir a partir daí, sem dúvida, diversificam-se. Não se limitam pelo exercício perigoso de uma interpretação excessivamente solitária e, portanto, abusiva do analista. Menos atribuição de sentido e mais recorrência de um certo jeito, de um certo modo de falar (Guirado, 1997)

Analisar pragmaticamente significa, principalmente, considerar o papel do contexto na produção do discurso, tomando toda fala como balizada por regramentos que definem e são definidos pelo modo de produção do discurso, pelas condições de possibilidade situadas em um dado lugar e momento termos esses (contexto, lugar, momento) produzidos pelo discurso do próprio analista, inclusive, cujos pressupostos constituirão o discurso (e a verdade) em análise. Desloca-se, pois, o foco analítico perguntando-se como se diz ao invés de o que significa o dito:

Dizer que o discurso é ato dispositivo é acentuar seu caráter de dizer, em vez de acentuar o dito, ou seja, é atentar para o que se mostra enquanto se diz: que tipo de interlocução se cria, que posição se legitima na asserção feita, que posição se atribui ao interlocutor, o jogo de expectativas criado na situação, como se respondem ou se subvertem tais expectativas, e assim por diante. [...] Qualquer sentido a que se chegue será uma construção que considere todo esse modo de produção, ou melhor, o contexto (em) que (se) produz a fala e suas razões (seus sentidos) (Guirado, 2000, p. 34)

\section{Considerações finais}

Ao fim do percurso, espera-se ter se ressituado a relação método-verdade no sentido de produzir algum reconhecimento da artificialidade das verdades metodologicamente forjadas, o que, de modo algum, as invalida: seus efeitos de verdade, sejam clínicos ou não, estão aí para mostrar que a construção da verdade não faz menos sentido do que sua descoberta.

Além do reconhecimento esperado no e pelo leitor, deve-se reconhecer que, se todo discurso é produzido de um lugar, não se pode fugir à própria lei. A escritura deste texto se dá também em um lugar discursivoinstitucional que permite reconhecimentos e desconhecimentos, e que é, ainda, atravessado por expectativas, situado no tempo e no espaço, constituído em e constituinte de relações de poder-saber... E disso, não se julga possível isentar-se através de qualquer método.

Em um retrocesso sintético do percurso traçado,

Podemos então supor, na nossa civilização e ao longo dos séculos, a existência de toda uma tecnologia da verdade que foi pouco a pouco sendo desqualificada, recoberta e expulsa pela prática científica e pelo discurso filosófico. A verdade aí não é aquilo que é, mas aquilo que se dá: acontecimento. Ela não é encontrada, mas sim, suscitada: produção em vez de apofântica. Ela não se dá por mediação de instrumentos, mas sim, provocada por rituais, atraída por meio de ardis, apanhada segundo ocasiões: estratégia, e não método. Desse acontecimento que assim se produz impressionando aquele que o buscava, a relação não é do objeto ao sujeito de conhecimento. É uma relação ambígua, 
reversível, que luta belicosamente por controle, dominação e vitória: uma relação de poder (Foucault, 2009a, pp. 114-115)

Essas relações de 'poder-saber' não devem então ser analisadas a partir de um sujeito do conhecimento que seria ou não livre em sua redação ao sistema do poder, mas é preciso considerar, ao contrário, que o sujeito que conhece, os objetos a conhecer e as modalidades de conhecimentos são outros tantos efeitos dessas implicações fundamentais de poder-saber e de suas transformações históricas. Resumindo, não é a atividade do sujeito de conhecimento que produziria um saber, útil ou arredio ao poder, mas o poder-saber, os processos e as lutas que o atravessam e que o constituem, que determinam as formas e os campos possíveis do conhecimento (Foucault, 2009d, p. 30)

Entende-se, finalmente, porque a AID propõe uma estratégia de pensamento, e não uma metodologia. O método, a estratégia eleita, define as condições de possibilidade das enunciações produzindo um objeto. E o mesmo ocorre com a verdade a ser atingida uma verdade produzida dentro de um campo discursivo, não uma verdade resguardada em uma exterioridade a ser desvelada. Assim, todo sentido aqui formulado o foi com atenção ao seu contexto, ao seu modo de produção e ciente de sua parcialidade. 


\section{Renee Volpato Viaro}

Mestre em Psicologia (Práticas Educacionais e Produção de Subjetividade) pela Universidade Federal do Paraná, PR - Brasil.

Email: reneevolpato@yahoo.com.br

\section{Luciana Albanese Valore}

Doutora em Psicologia Escolar e do Desenvolvimento Humano, Professora Associada do Departamento de Psicologia da Universidade Federal do Paraná, PR - Brasil.

E-mail: luvalore@uol.com.br

Endereço para envio de correspondência:

Praça Santos Andrade, 39, apto 63, Centro, Curitiba, PR - Brasil. CEP 80020-300

Recebido 10/8/2010, Aprovado 12/8/2011. 


\section{Referências}

Birman, J. (2002). Jogando com a verdade. Uma leitura de Foucault. Physis: Rev. Saúde Coletiva, 12(2), 301-324.

Candiotto, C. (2006). Foucault: uma história crítica da verdade. Trans/Form/Ação, 29(2), 65-78.

Foucault, M. (1980). Nietzsche, Freud e Marx. Porto, Portugal: Anagrama.

Foucault, M. (1984). História da sexualidade I: a vontade de saber (5a ed.). Rio de Janeiro: Graal.

Foucault, M. (2005). A arqueologia do saber (7a ed.). Rio de Janeiro: Forense Universitária.

Foucault, M. (2007). As palavras e as coisas: uma arqueologia das ciências humanas (9a ed.). São Paulo: Martins Fontes.

Foucault, M. (2008). A ordem do discurso (18a ed.). São Paulo: Loyola.

Foucault, M. (2009a). A casa dos loucos. In M. Foucault, Microfísica do poder (27a ed., pp. 15-38). Rio de Janeiro: Graal.

Foucault, M. (2009b). Nietzsche, a genealogia e a história. In M. Foucault, Microfísica do poder (27a ed., pp. 15-38). Rio de Janeiro: Graal.

Foucault, M. (2009c). Verdade e poder. In M. Foucault, Microfísica do poder (27a ed., pp. 1-14). Rio de Janeiro: Graal.
Foucault, M. (2009d). Vigiar e punir: nascimento da prisão (36a ed.). Petrópolis, RJ: Vozes.

Guirado, M. (1986). Psicologia institucional. São Paulo: EPU.

Guirado, M. (1995). Psicanálise e análise do discurso: matrizes institucionais do sujeito psíquico. São Paulo: Summus.

Guirado, M. (1997). Vértices da pesquisa em psicologia clínica. Psicologia USP, 8(1). Recuperado em 14 junho 2010, dehttp:// www.scielo.br/scielo/

Guirado, M. (2000). A clínica psicanalítica na sombra do discurso: diálogos com aulas de Dominique Maingueneau. São Paulo: Casa do Psicólogo.

Guirado, M. (2010). A análise institucional do discurso como analítica da subjetividade. São Paulo: Annablume.

Ribeiro, C. R. (2007). Sujeito-dobradiça: metáfora de subjetividade, metonímia institucional. In M. Guirado, \& R. Lerner (Orgs.), Psicologia, pesquisa e clínica: por uma análise institucional do discurso (pp. 245-262). São Paulo: Annablume, Fapesp. 